\title{
Research on the Development Path and Strategy of the "Belt and Road" Land Logistics Path
}

\author{
Xing-jian Zhou ${ }^{1,2,}$, Jian-ya Zhou ${ }^{3},{ }^{\text {Jin }}$ Yang $^{4}$ and Zhen $\mathrm{Ai}^{5}$ \\ ${ }^{1}$ School of Management, Wuhan Textile University, Wuhan, China \\ ${ }^{2}$ Research Center of Enterprise Decision Support, Hubei Province Research Base for Humanities and Social Sciences, \\ Wuhan, China \\ ${ }^{3}$ Logistics College, Wuhan Technology and Business University, Wuhan, China \\ ${ }^{4}$ Logistics College, Wuhan Technical College of Communications, Wuhan, China \\ ${ }^{5}$ Logistics Productivity Center, Hubei Material Circulation Technology Research Institute, Wuhan, China \\ Email: wuliuwtu@163.com
}

\begin{abstract}
The "belt and road" is essentially the realization of more convenient circulation of production. The land logistics path is an important connotation and an important means to promote the construction of "one belt and one road". By analyzing the demand relationship between the comprehensive and key points, the pointand line, the inside and outside, and between the stock and the increment in the development of the land logistics path, combined with the factors affecting the development, we construct three paths for the development of the "one belt and one way" land logistics path. Then, based on the industrial stickiness of logistics channels, five channels are planned, including the Asia-Europe Roadbridge logistics path, the China-Mongolia-Russia logistics path, the China-Pakistan logistics path, the Mongolia-China-India-Myanmar logistics path and the China-South Peninsula logistics path. Special departments and organizations are used to organize and manage the logistics path operation effectively.
\end{abstract}

Keywords: "belt and road", land logistics path, regional international logistics

\section{“一带一路”陆上物流通道发展路径与策略研究}

\author{
周兴建 ${ }^{1,2, \#,}$, 周建亚 ${ }^{3}$, 杨晋 ${ }^{4}$, 艾振 ${ }^{5}$ \\ 1 武汉纺织大学 管理学院, 湖北 武汉 430073 \\ 2 湖北省人文社会科学研究基地 企业决策支持研究中心, 湖北 武汉, 430073 \\ 3 武汉工商学院 物流学院, 湖北 武汉 430063 \\ 4 武汉交通职业技术学院 物流学院, 湖北 武汉 430065 \\ 5 湖北省物资流通技术研究所 物流生产力中心, 湖北 武汉 430071 \\ Email: wuliuwtu@163.com
}

\begin{abstract}
摘要: “一带一路” 本质上是实现生产要素更加顺畅便捷地流通, 其中陆上物流通道建设则是 “一带 一路” 的重要内涵之一，也是推动 “一带一路” 建设的重要手段之一。通过分析 “一带一路” 陆上物 流通道发展中全面与重点之间、点线面之间、内与外之间以及存量与增量之间的需求关系，结合 “一 带一路” 陆上物流通道发展影响因素, 构建 “一带一路” 陆上物流通道发展的三种路径。进而基于物 流通道的产业粘性, 规划亚欧大陆桥物流通道、中蒙俄物流通道、中巴物流通道、孟中印缅物流通道、 中国一中南半岛物流通道等五条通道, 并成立专门的部门和组织对通道运行进行有效的组织和管理。
\end{abstract}

关键词: “一带一路”, 陆上物流通道, 区域国际物流 


\section{1 引言}

“一带一路” 建设是通过生产要素更加顺畅便捷地流通, 构建包括沿线各国在内的自由开放的经济体系 [1]。在 “一带一路” 流通体系中, 物流通道既是最重要的内涵之一, 又是实现 “一带一路” 建设不可或 缺的重要手段 ${ }^{[1]}$ 。物流是经济发展的引致需求, “一带一路” 通过纵贯欧亚大陆的贸易通道和产业通 道，把分散的地区经济串联起来。而沿线国家相互贸易与投资的增加、产业转移的加速，势必会大量增 加沿线物流流量 ${ }^{[3]}$ 。同时，“一带一路” 物流通道的畅通和区域国际物流规模的扩大也能使各区域经济 更好地融合, 促进欧亚大陆要素市场、产业链、产业集群的进一步整合, 从而以点带线、以线带面, 形 成更加统一、紧密联系的经济体 ${ }^{[4]}$ 。“一带一路” 物流通道涉及到多个国家与地区间的跨区域物流运 营, 其实质为国际物流范畴下的跨区域物流通道建设问题[5]。现有关于国际物流通道建设的研究, 也主 要是在这一理论范畴下展开的。

国际物流通道是物品从供应地到接收地所跨越不同国家或地区而经过的一切陆路、水路和航空线路及 各自对应运输方式的总和 [6]。对于国际物流通道的理解, 首先, 物品要跨越国家或地区之间的边界, 也 即要发生物理上的位置移动, 因此国际物流大通道是物品跨域国境的位移离不开一定的运输工具及适合 这种运输工具的道路。其次, 在商业经济活动中, 物质资料的跨国运输要面临各种各样的风险, 为了降 低物流成本，一方面需要每一种运输方式附加运输、储存、装卸、搬运、包装、流通加工、配送、回 收、信息处理等等环节, 另一方面也时常需要多种运输方式的组合, 或是海铁联运, 或是铁路和公路联 运, 乃至海陆空联合运输, 因此国际物流通道建设在于减少物品运输过程的损耗, 降低物流成本, 同时 在运输过程适当增加一些物流环节，以在不同运输方式间展开协同。最后，在国际物流配送过程中，物 品要从一个国家或地区运往另一个国家或地区, 必然要途径不同的区域, 因此国际物流通道内生的具备 跨区域性特点, 也就意味着国际货物在运输过程中, 不管采用何种运输方式和选择何种运输道路, 都要 途经两个或两个以上的国家或区域。

结合《推进物流大通道建设行动计划（2016-2020 年）》对物流大通道的界定，本研究将跨区域国际物 流通道界定为: 在特定地域范围内, 由陆路、水路和航空线路综合构成的服务于国际货物运输的货物流 动走廊 ${ }^{[7]}$ 。跨区域国际物流通道具有地域性、系统性、综合性、开放性等四大特征 ${ }^{[8]}$ 。

(1) 地域性特征表现为国际物流通道中各种运输道路和方式在地理空间上具有特定的范围, 这个区域 的范围或者限定于行政区划, 或者根据不同道路的功能属性来界定;

(2) 系统性特征表现为物流通道中不同运输方式虽然各成体系，但是国际货物运输往往涉及不同运输 方式之间的衔接, 跨区域国际物流通道内各条运输线路和运输方式需要有机衔接、相互协作才能完成跨 区域、跨国界运输 ${ }^{[9]}$;

(3) 综合性特征表现在区域范围内存在多种线路和运输方式, 需要综合多种运输方式的优缺点, 采取 多种运输方式开展货物的跨区域、跨国界运输;

(4) 开放性特征要求通道内所有物流基础设施建设不仅仅满足于本区域物流需要, 还要在链接其他国 家物流设施同时对周边区域开放，吸引大量的国际物流途径本区域的物流通道。

现有关于跨区域国际物流通道研究的文献相对较少, 随着国家 “一带一路” 战略的纵深不断发展, 沿 线国家及地区之间经贸合作往来越来越频繁，尤其是陆上丝绸之路经济带国家与地区间的合作强度不断 加深, 面向合作区域和国家的国际物流通道建设显得极为重要。随着时间的推移和物流通道的不断建设 与完善, 面向某个特定国家和地区的跨区域国际物流通道就会突出呈现。因此, 对于 “一带一路” 陆上 物流通道发展需求、发展路径及发展策略等规划的研究也极为必要。

\section{2 “一带一路”陆上物流通道发展需求分析}

“一带一路” 陆上物流通道不是传统的运输通道概念, 而是国际产能合作与中西部内陆地区双向开放的 产业走廊概念, 是沿线多个产业布局点进行通盘考虑与合作的概念。因此, 要站在通道和枢纽结合的层 面看, 按照现代产业基于物流供应链组织方式的变革和沿着通道、枢纽来做产业布局发展的文章, 实现 产业价值链提升和推动发展模式创新 ${ }^{[10]}$ 。

对于 “一带一路” 陆上物流通道的发展, 涉及通道类型划分、通道规划建设、通道互联互通等问题, 需要在目前主要以交通运输功能为核心的基础上, 从供给侧结构性改革角度, 做好通道沿线和重要城市 的产业承载和产业布局发展, 实现以运输带物流、以物流带产业、以产业带动区域经济发展的经济、产 业发展方式的转变, 提高产业布局竞争力, 有效降低产品辐射成本, 推动经济由粗放型增长方式获取低 端加工利润, 转向主要靠供应链的控制力和价值链的增值力来获得收益, 探索经济后发地区发展能力的 突破 ${ }^{[1]}$ 。因此，在 “一带一路”陆上物流通道发展规划中，需要考虑如下几个方面的需求关系: 


\section{1 全面与重点之间的需求关系}

“一带一路” 涉及面广、建设内容复杂, 推动 “一带一路” 陆上物流通道建设必须坚持循序渐进、重点 突破的原则。一是妥善推进沿线重点国家、重点地区物流通道建设, 坚持一国一策、因地制宜。一些国 家和地区是 “一带一路” 陆上物流通道的重要途经地, 区位优势明显, 必须积极推动过境通道建设。二 是积极推动重点工程建设。互联互通设施不完善是 “一带一路” 陆上物流通道发展中最大的问题, 要在 统筹设计好 “一带一路” 物流通道建设方案的基础上, 着力打通关键瓶颈, 形成物流通路。三是抓住流 通便利化、标准统一化等重点方面, 完善 “一带一路” 陆上物流通道, 进而推动贸易自由化、经济一体 化。

\section{2 点、线、面之间的需求关系}

“一带一路” 物流通道发展是一项复杂的系统工程, 包括物流节点、物流通道、物流辐射区域等功能主 体。推进 “一带一路” 物流通道建设必须合理把握各功能主体之间的关系。这意味着一方面要做好各功 能主体的分工, 另一方面要确保节点、通道、区域功能的科学衔接, 形成组合力量、综合优势和集成优 势, 使物流节点和通道建设能更好地支持区域经济发展, 同时也使区域发展为节点和通道创造更大的物 流需求，形成相互支撑、相互促进的良性互动格局。

\section{3 内与外之间的需求关系}

“一带一路” 战略的推进, 我国对外贸易、对外投资、产业转移的总量、流向、结构都将发生新变化, 要求物流体系必须进行适应性调整, 形成国内外物流通道的对接, 形成内外互动、内外互补、内外互通 的新格局。一方面, 继续加强我国内陆腹地与沿海地区的物流联系, 完善海上运输通道建设; 另一方 面, 加强内陆腹地地区与沿边地区的物流联系, 加强东北、西北、西南陆上物流通道建设, 形成内陆地 区对外联系的新通道，使内陆地区、边疆地区成为对外开放、联通全球的新高地。

\section{4 存量与增量之间的需求关系}

随着全球化和区域经济一体化的推进，欧亚大陆国家经贸往来已产生和积累大量存量物流资源。在 “一 带一路” 陆上物流通道发展过程中, 要处理好这些存量资源和增量资源的关系。具体看, 主要包括四方 面: 一是处理好各国已有物流规划、战略和新的战略、设计、构想之间的关系。“一带一路” 沿线各国 在不同时期提出了各种交通物流发展规划、战略。“一带一路” 陆上物流通道发展需要综合考虑各国发 展诉求, 统筹规划和设计, 实现整体利益最大化。二是处理好既有物流通道设施和新增通道设施之间的 关系, 必须在统一规划的基础上, 明晰 “一带一路” 陆上物流通道的构成和布局, 对正在运行或已建成 的重要物流通道设施, 要进一步强化其功能, 同时积极推动缺失的关键瓶颈通道建设, 实现既有通道和 新增通道的对接与联通。

\section{3 “一带一路”陆上物流通道发展路径}

\section{1 陆上物流通道发展影响因素}

结合 “一带一路” 陆上物流通道发展需求分析, 这种跨区域的陆上国际物流通道建设属于一项综合系统 工程, 其影响因素包括:

（1）地理因素。建设 “一带一路” 陆上物流通道，在修建公路、铁路及物流园区、物流集散中心等物 流基础设施时候, 自然地理环境无疑是最直接的影响因素。

(2) 需求因素。国际贸易和跨国企业全球范围经营活动的开展, 衍生出来的国际物流需求也极大促进 各国和地区加快本区域国际物流通道建设进程。区域国际物流需求水平的高低也影响 “一带一路” 陆上 物流通道建设的质量优劣。

(3) 技术因素。与国际物流大通道建设相关的物流技术、交通运输装备制造技术、各种道路建设技 术、网络通讯技术等等技术及其产业化程度也极大影响着 “一带一路” 陆上物流通道建设。这些技术条 件既包括当前全球最先进的技术, 也包括本区域自身拥有的相关技术，还包括区域整合其他地区的技术 并使其标准化后的技术。

(4) 经济因素。经济实力对 “一带一路” 陆上物流通道建设的影响更多地表现为区域能否从经济层面 给予本地区国际物流通道建设提供经济支撑。合理的产业布局将有利于物流通道内各要素围绕产业发展 所需的物质资料进行分工合作，从而极大拉动区域国际物流通道建设。 
（5）政治因素。一国或地区政府如何看待建 “一带一路” 陆上物流通道在本地区中的地位和作用无疑 是重要的影响因素, 至于政府为推动区域国际物流大通道建设而制定各项规划、政策、体制机制, 也都 是基于政府意志演化而来的影响。

\section{2 陆上物流通道建设路径选择}

在上述影响因素下，“一带一路”陆上物流通道建设可以选择如下路径:

(1) 陆上物流通道与开放型产业联动发展路径。本地区产业要开放发展, 需参与国际市场竞争, 也要 求区域物流基础设施建设周边国家和地区开放，不仅承接本地区开放型产业发展衍生出来的国际物流需 求, 也要承担周边国家和地区开放型产业发展对本区域国际物流基础设施的物流需求, 从而实现物流通 道的国际化和高效通畅 ${ }^{[12]}$ 。

(2) 陆上物流通道与国际性城市耦合发展路径。按照区域城镇化发展过程中与交通道路耦合发展的模 式，寻求符合 “一带一路” 沿线地区发展实际的建设路径。在陆上物流通道建设中需要修缮之前无法承 担国际物流的原有物流通道, 或者重新规划建设今后能够满足高频次、大批量的物质交换的国际物流基 础设施。

（3）“一带一路” 沿线区域政府基于国家安全需要主推建设路径。“一带一路” 沿线区域政府主推建 设的物资通道能够开放用于国际物流, 将极大促进本区域开放型经济发展, 提升本区域综合实力, 更有 利于国家安全和稳定。

\section{4 “一带一路”陆上物流通道发展策略}

\section{1 基于产业粘性的陆上物流通道发展模式}

产业粘性是指对产业集聚与转移的作用和作用力，“一带一路” 陆上物流通道的产业粘性通过促进产业 发展, 吸引产业在通道内聚集, 阻缓产业离开通道进行转移 ${ }^{[13]}$ 。“一带一路” 陆上物流通道对产业的作 用一方面表现为为产业发展提供基础设施和发展条件，促进产业的发展，形成产业集聚; 另一方面表现 为产业转移的阻力, 在产业发生转移或梯度转移时, 滞缓产业发生转移。从 “一带一路” 陆上物流通道 角度看, 跨区域国际物流通道的形成和发展对通道内及周边的产业有吸附、牵引和阻滞作用等。从产业 角度讲，产业对 “一带一路” 陆上物流通道具有依附性、随迁性、转移惰性等。通过跨区域国际物流通 道干线和物流节点的衔接，形成物畅其流、经济便捷的综合国际物流体系，降低区域间物流成本、提高 物流速度、加强对货物的保障, 有效提升跨区域间物流集聚和辐射效益, 吸引区域产业集聚 ${ }^{[14]}$ 。“一带 一路” 陆上物流通道发展离不开利用通道来获取各自利益的物流服务供给群体和对应的需求群体，同 时, 跨区域国际物流通道也只有在供需双方多频次、高强度参与情况下, 才能够发挥通道本身的作用, 实现通道自身的价值，进而再继续促进政府和市场力量投入更多资源完善通道各方面的功能，推动 “一 带一路”陆上物流通道发展。

\section{2 陆上物流通道的发展布局与总体规划}

“一带一路” 陆上物流通道建设在区域已有的物流基础设施基础上，即便是专门建设的国际物流通道， 无不例外都要加大公路、铁路、航空机场、港口码头、油气管道等运输线路建设, 因为这些运输线路直 接决定了国际货物运输工具能否顺畅运行 ${ }^{[15]}$ 。特别在商业社会中, 应用先进技术, 高水准建设的基础设 施, 将能够极大降低区域国际货运成本, 增强区域国际物流竞争力。同时, 涉及跨区域、长距离、高强 度的国际物流运输, 没有布局合理的物流枢纽, 物流通道的通畅将难以保证 ${ }^{[16]}$ 。因此, 根据物流通道的 产业粘性, “一带一路”陆上物流通道主要布局及规划如下。

1. 亚欧大陆桥物流通道

亚欧大陆桥物流通道主要依托亚欧大陆桥、新亚欧大陆桥两条铁路所形成的横跨欧亚大陆的物流大动 脉, 也是联通太平洋和大西洋的陆上物流大动脉。根据目前已形成的和未来可能形成的物流流向, 亚欧 大陆桥物流通道可分为三个方向:

(1) 依托亚欧大陆桥或西伯利亚大陆桥的物流通道，起自俄罗斯东部的符拉迪沃斯托克，横穿西伯利 亚至莫斯科，再至欧洲，最后达到荷兰鹿特丹港，经过俄罗斯、哈萨克斯坦、白俄罗斯、波兰、德国、 荷兰 6 个国家, 全长约 13000 公里。由于亚欧大陆桥铁路运营时间较早, 特别是较早采用了多式联运方 式, 该物流通道也较早地发挥了联通欧亚大陆的作用, 但其主要是联通俄罗斯东部和西部地区、俄罗斯 西部和欧洲地区及少部分日本至欧洲的陆路运输，覆盖国家少，辐射范围窄，物流量相对有限。 
（2）依托新亚欧大陆桥的物流通道, 该通道起自我国的连云港, 途径哈萨克斯坦、俄罗斯、白俄罗 斯、波兰等国, 直达欧洲, 最终到达荷兰的鹿特丹, 全长 10900 公里, 辐射亚欧大陆 30 多个国家和地 区, 成为横跨亚欧两大洲、连接太平洋和大西洋, 实现海一陆一海统一运输的第二条国际大通道。与亚 欧大陆桥相比, 新亚欧大陆桥地理位置和气候条件更加优越, 港口无封冻期, 吞吐能力大, 陆上距离更 短, 经济成本更加明显, 且辐射面更广, 因此物流需求更大。随着新亚欧大陆桥建设的推进, 目前该通 道的起点已远不止连云港一个城市, 我国东部各主要沿海城市都与亚欧大陆桥形成了联通, 这些城市又 与韩国、日本、东南亚等国家与地区通过海上航线相连，形成了多条新亚欧大陆桥物流通道的延伸线。 同时, 我国中西部的乌鲁木齐、西安、武汉、重庆、南宁、郑州等城市也能经阿拉山口、霍尔果斯等口 岸与新亚欧大陆桥物流通道相连接, 把我国广大中西部地区纳入新亚欧大陆桥物流通道中, 进一步扩大 新亚欧大陆桥的辐射范围，推进沿线地区由物流至经济的全方位互联互通。

（3）由我国至中亚和波斯湾地区的第三条物流通道。中亚、西亚地区能源资源十分丰富，中国、欧洲 对该地区能源资源均有较大需求, 该条物流通道建设十分必要。这一物流通道可能有两个方向: 一是从 我国霍尔果斯、阿拉山口等口岸出境后至哈萨克斯坦, 再由哈萨克斯坦南下至土库曼斯坦、伊朗, 再向 西至土耳其。二是由我国喀什通往吉尔吉斯斯坦, 再进乌兹别克斯坦(中吉乌铁路), 再南下伊朗并至土 耳其。这一通道有助于形成欧亚大陆中部地区能源资源供给、两端东亚和欧洲生产加工的物流大循环。

2. 中蒙俄物流通道

中蒙俄物流通道是起自我国京津冀和东北地区, 经蒙古通往俄罗斯, 联通三国的物流大通道。该物流 通道主要有两条路线: 一是从华北京津冀地区到呼和浩特, 再到蒙古和俄罗斯, 最终可到俄罗斯的波罗 的海沿岸。二是从我国东北地区, 经满洲里和赤塔通往俄罗斯。这两个通道互动互补, 共同构筑成中蒙 俄三国经贸往来的大动脉。中蒙俄三国经济互补性强, 蒙古、俄罗斯矿产和能源资源较为丰富, 而中国 是全球最大的资源能源进口国之一, 是蒙俄两国资源能源产品出口的重要市场; 中国制造业较为发达, 蒙俄两国对中国轻工产品具有较高的依赖度。产业结构互补决定该物流通道将具有较大的双向物流需求 量。

3. 中巴物流通道

中巴经济走廊是 “一带一路” 建设的旗舰项目。随着中巴基础设施互联互通建设的逐步推进，中巴物 流通道逐步形成维形，并将发挥越来越大的作用。该通道起自我国喀什，通过红其拉甫口岸进入巴基斯 坦, 经伊斯兰堡、拉合尔, 至印度洋的瓜达尔港。该通道向东可延伸至我国内陆地区, 向西可进入伊 朗、伊拉克和土耳其, 向南可进入印度洋并与海上丝绸之路对接, 成为我国向西开放、巴基斯坦向东开 放的战略大通道。这条通道一方面有利于我国西北特别是新疆对外开放, 相比新疆过去经由西太平洋水 域与南亚、中东和非洲的贸易往来将缩短上万公里; 另一方面, 该通道也是能源物流通道, 来自中东的 油气资源可由瓜达尔港登陆。该物流通道建设有利于形成我国后方新的能源运输通道, 保障我国能源安 全。

4. 孟中印缅物流通道

南亚地区人口多、面积广、发展潜力大, 未来将成为世界经济的重要增长极之一。除中巴物流通道 外, 孟中印缅物流通道是中国与南亚和印度洋地区联通的另一条大动脉。孟中印缅物流通道起自我国昆 明, 向西经缅甸、印度东北部地区、孟加拉国至加尔各答, 一边可通过云南辐射我国内陆广大地区和中 南半岛地区, 另一边可辐射印度腹地地区, 联通南亚、东亚、东南亚三大经济板块。孟中印缅物流通道 可以有四条线路: 北线从昆明经腾冲至缅北的密支那, 经雷多口岸进入印度东北部, 再向南至孟加拉国 的达卡和印度的加尔各答; 中线从昆明经瑞丽口岸至缅甸曼德勒, 再向西经印度东北部的英帕尔至达卡 和加尔各答; 南线包括两条线路, 一条由昆明经曼德勒至盿漂港, 再北上至吉大港、达卡和加尔各答, 另一条由昆明至曼德勒后, 向南到缅甸仰光。虽然中国西南地区、印度东北部地区、缅甸、孟加拉国相 对而言均不发达, 但如果建成孟中印缅物流走廊, 将会显著增进各国经贸联系, 并将加快这一地区融入 全球经济大循环的步伐。

5. 中国一中南半岛物流通道

中国一中南半岛物流通道起自我国的广东、广西、云南等省 ( 区) ，南下贯穿越南、老挝、柬埔寨、 泰国和马来西亚等中南半岛五国, 直抵新加坡。现阶段, 中国一中南半岛的物流形式以海运和部分边境 公路运输为主。海运上, 我国珠三角、北部湾及长三角港口群可从海路直接与除老挝外的所有中南半岛 国家对接; 公路上, 我国广西和云南可直接通过边境口岸与越南、老挝对接, 进而向南辐射到泰国、柬 埔寨等地。随着铁路建设的推进, 未来铁路物流将在该通道中发挥更加重要的作用, 形成以铁路物流为 主，公路物流、海运物流为补充的中国至中南半岛的南北向物流格局。

\section{3 陆上物流通道建设组织与管理}

“一带一路” 陆上物流通道包括海陆空多条线路和庞大的综合运输体系，要保证国际货物在通道内顺畅 流转, 就需要专门的部门和组织对通道运行进行有效的组织和管理。从管理学的角度, 也就是对 “一带 
一路” 物流大通道中各部分进行充分的计划、组织、领导、协调和控制 [17]。这方面政府能够对区域国际 物流通道进行规划、设计与管理, 但是政府作为一个多部门构成的组织, 每个部门承担一定的职责和从 事相应的管理工作，有时候还存在重复管理、交叉管理情形 188 。为此，在 “一带一路” 陆上物流通道建 设中，需要在通道干线的规划、物流枢纽的选址与布局、物流服务商的组织与管理、物流信息网络系 统、相关制度政策的制定等方面, 落实具体任务到相应的政府部门, 形成至上而下的组织体系, 同时要 构建有效的管理机制，保证 “一带一路”陆上物流通道建设能够政令畅通，各项工作高效衔接。

\section{5 结论}

综合考虑地理因素、需求因素、技术因素、经济因素和政治因素, “一带一路” 陆上物流通道建设可以 采用陆上物流通道与开放型产业联动发展路径、陆上物流通道与国际性城市耦合发展路径以及 “一带一 路” 沿线区域政府基于国家安全需要主推建设路径。结合物流通道的产业粘性, “一带一路”陆上物流 通道主要规划为亚欧大陆桥物流通道、中蒙俄物流通道、中巴物流通道、孟中印缅物流通道、中国一中 南半岛物流通道等五条通道。同时, 形成专门的部门和组织, 针对通道规划、物流网络及产业发展制定 相关制度政策、构建有效的管理机制，对 “一带一路” 陆上物流通道建设进行有效的组织和管理。

致谢. 本文得到 2019 年中国物流与采购联合会、中国物流学会研究课题面上项目（2019CSLKT3-145） 的资助，是其阶段性成果。

\section{参考文献}

1. 李宏. “一带一路”为物流产业带来了什么? [N]. 现代物流报,2019-04-29(A01).

2. 汪鸣.物流通道与枢纽结合 推动枢纽经济发展[J].中国远洋海运,2018(11):44-45

3. 赵辉.“一带一路”下国际贸易与国际物流协同发展探究[J].合作经济与科技,2019(10):112-114.

4. 陈文玲,梅冠群.“一带一路”物流体系的整体架构与建设方案[J].经济纵横,2016(10):19-26.

5. 王博,祝宏辉,刘林. 我国 “一带一路”沿线区域物流效率综合评价一一基于三阶段 DEA 模型 [J]. 华东经济管 理, 2019(05):76-82

6. 黄伟新.区域国际物流大通道建设:内涵、影响因素及推进路径[J].市场论坛,2018(08):4-9

7. 钟德才. “一带一路” 战略下国际物流通道建设问题研究[J].中国商论,2017(07):96-97

8. 李苗. “一带一路” 背景下陆桥物流系统运行机制研究[D].长安大学, 2017

9. 本刊编辑部.多式联运畅通“一带一路”物流通道[J].大陆桥视野,2019(04):7.

10. 林备战."一带一路"国际物流通道建设进行时[J].中国远洋海运,2018(03):64-67+8-9

11. 魏颖琦. 一带一路建设助推经贸合作走向深入 [N]. 中国社会科学报,2019-06-03(003).

12. 弓联兵,马天宇. “一带一路”背景下国内节点城市协同发展的动力条件与路径机制 [J/OL].青海社会科学, $2019(02): 5$ $0-57$.

13. 赵光辉. 畅通 “一带一路” 沿线国物流节点通道[N]. 贵州日报,2018-10-16(017)

14. 刘洁, 付新平, 何瑜莎. 物流通道产业粘性测度模型及其实证研究 [J]. 北京邮电大学学报 (社会科学 版),2018,20(06):74-79+96

15. 徐剑, 李周奇, 林国志. “一带一路” 背景下中国区域物流网络模型研究 [J]. 沈阳工业大学学报 (社会科学 版), 2019,12(01):37-46

16. 周克全. 构筑复合型国际物流通道与通道经济 [N]. 甘肃日报,2018-05-25(009)

17. 范月娇. 物流通道的区域经济聚散机制及其集聚效应检验一一基于中国 11 条物流通道的实证 [J]. 中国软科 学, 2018(02):103-117

18. 江志娟,董千里. 丝绸之路经济带省域空间联系与物流枢纽布局[J].中国流通经济, 2016,30(08):5-13 